Article

\title{
Influence of Mothers' Nutrition Knowledge and Attitudes on Their Purchase Intention for Infant Cereal with No Added Sugar Claim
}

\author{
Tzu-Yun Chien ${ }^{1}$, Yi-Wen Chien ${ }^{1}{ }^{(D)}$, Jung-Su Chang ${ }^{1,2}$ and Yi Chun Chen ${ }^{1, *(D)}$ \\ 1 School of Nutrition and Health Sciences, Taipei Medical University, Taipei 110, Taiwan; \\ b506100083@tmu.edu.tw (T.-Y.C.); ychien@tmu.edu.tw(Y.-W.C.); susanchang@tmu.edu.tw (J.-S.C.) \\ 2 Graduate Institute of Metabolism and Obesity Sciences, College of Nutrition, Taipei Medical University, \\ Taipei 110, Taiwan \\ * Correspondence: yichun@tmu.edu.tw; Tel.: +886-(2)2736-1661 (ext. 6559)
}

Received: 5 February 2018; Accepted: 28 March 2018; Published: 30 March 2018

check for updates

\begin{abstract}
A higher sugar intake in infancy might result in a predisposition to a higher sugar intake in later childhood. In Taiwan, many commercial infant and toddler foods with nutrition claims have high sugar content. This study explored the influence of mothers' knowledge and attitudes on their purchase intention for infant food with nutrition claims. This study was a cross-sectional survey. An online survey was distributed to 940 mothers who had a child aged between 4 months and 3 years; $40 \%$ of mothers tend to misunderstand that "no added sugar" (NAS) indicates no sugar or less sugar content and, thus, that NAS infant cereal is healthy. Approximately $50-70 \%$ of mothers believe that NAS infant cereal is more natural, healthier, and contains less sugar. Attitude toward the NAS claim was found to be a mediating variable between sugar-related knowledge and purchase intention. The lower the level of sugar-related knowledge was, the more positive the attitude toward NAS infant cereal and the higher the purchase intention for NAS infant cereal were. In the future, regulation of no added sugar is needed to avoid the misleading information and mothers' sugar-related knowledge need to be improved through nutrition education.
\end{abstract}

Keywords: sugar; no added sugar; mother; infant; nutrition knowledge; attitude; purchase intention

\section{Introduction}

Overweight and obesity can increase the risk of many health problems, including diabetes, heart disease, and certain cancers [1-3]. The World Health Organization (WHO) reported that in 2015, the number of overweight children under the age of 5 was estimated to be more than 42 million globally, and almost half of all overweight children under 5 years old live in Asia [4]. Compared with the 2015 data of the World Obesity Federation, the overweight rates of children in Taiwan were the highest in Asia (boys: $26.1 \%$, girls: $21.4 \%$ ) [5]. High sugar intake is of concern because of its association with poor dietary quality and obesity [6]. The American Heart Association indicated that both adults and children weight gains over the past 30 years were related to increased sugar intake [7]. Several studies have also confirmed that children who consume more sugar have a higher obesity rate than those who consume less sugar [8-10].

The WHO defined sugar intake as the consumption of added sugar and natural sugar present in syrups, fruit juices, and fruit juice concentrates and recommended reducing the free sugar intake to less than $10 \%$ of total energy intake in both adults and children [11]. Notably, children in Western countries obtained approximately $16-26 \%$ of calories from sugar [12]. Two nutrition surveys in Taiwan revealed that free sugar intake from snacks and beverages contributed to $>10 \%$ of calories in children's total energy intake [13,14]. 
The introduction of complementary foods to infants is a critical transition in the development of their eating behavior. The taste preference for sugar is mostly innate [15]. Sugar contributes to the overall pleasure and enjoyment of food. Although genetically related individual differences exist, repeated offering of certain foods can modify innate preferences [16]. Foterek et al. observed that a higher free sugar intake in infancy might result in a predisposition to a higher free sugar intake in later childhood [17].

Commercial complementary foods are convenient for parents to include in their infants' diet. However, two surveys in the United States found that numerous commercial infant-toddler foods, snacks, and desserts had added sugars or high sugar content $[18,19]$. In Taiwan, $54.4 \%$ of 363 commercial complementary foods contained $>10 \%$ calories from sugar [20]. When parents purchased infant or toddler food, they considered the information on the food package, including the picture, brand, nutrition label, and claims [21,22]. Munsell et al. found that parents preferred products with claims such as "low-calorie", "real/natural", "vitamin C" and "antioxidants" when they purchased sugar-sweetened beverages (SSBs) for their children, even though these SSBs were also nutrient-poor [23]. An online survey found that nutrient claims on unhealthy products led parents to perceive these products to be more healthy and made them more likely to select these products [24]. The other study also found that nutrition claim on high-sugar cereals misled parents to believe these products to be a good nutritional quality and parents had greater willingness to buy them [25]. Thus, it appears that health and nutrition claims can be very misleading and parents really need to understand the nutrition labels and information well to be able to distinguish between correct claims and misleading claims.

Previous studies have reported that parents' nutrition-related knowledge and attitudes influence their feeding behavior toward children [26,27]. Consumers who lack nutrition knowledge may be limited in their ability to understand and evaluate health claims [28]. By contrast, consumers with greater nutrition-related knowledge can use nutrition labels to avoid misunderstanding products based on health claims [29]. Andrews et al. suggested that the negative relationship between nutrition-related knowledge and motivation to buy food with nutrition claims should be strengthened [30]. A previous study in Taiwan found that compared to infant food without "no added sugar" (NAS) claims, a higher percentage of NAS infant food contained more than $10 \%$ calories from sugar [20]. Also, few studies have investigated whether mothers' nutrition-related knowledge and attitudes affect their decision to purchase children's food with nutrition claims. Therefore, this study investigated mothers' sugar-related knowledge and attitudes and the influence of these factors on the mothers' purchase intention for infant cereal with sugar-related claims.

\section{Materials and Methods}

\subsection{Study Design and Sample}

This study was a cross-sectional survey. An anonymous and voluntary online survey was conducted through SurveyMonkey. Data were collected from May 2017 to July 2017. Various parenting social networks (e.g., BabyHome, mothers' groups on Facebook, and BabyMother on a bulletin board system) were approached, and those who agreed to distribute or advertise the study posted a link to the online questionnaire on their networks. The opportunity to win commercial vouchers (NT\$200) was used as an incentive. Mothers who lived in Taiwan, spoke Chinese, had a child aged between 4 months and 3 years, were their child's primary caregiver, and had fed their child infant cereal were eligible for the study. Those who had duplicate IP addresses and who did not finish the questionnaire were excluded. The study protocol was approved by the Taipei Medical University-Joint Institutional Review Board (N201608046). Informed consent was obtained from participants through screening questions before the completion of the main questionnaire.

In accordance with data collected in previous studies [26,27], the questionnaire comprised several parts. First, we collected the demographic characteristics of the mothers, including age $(\leq 30,31-34$, 
or $\geq 35$ years), education ( $\leq$ high school, undergraduate, or $\geq$ graduate), medical background (mother were health professional, such as medical doctors, dietitians or nurses:yes or no), parity (child was firstborn or non-firstborn), household monthly income ( $\leq \mathrm{NT} \$ 50,000$ or $>\mathrm{NT} \$ 50,000)$, and child's age (4-12 months, 13-24 months, or 25-36 months). The second part of the questionnaire assessed sugar-related knowledge, and the third part focused on mothers' sugar-related attitudes and health awareness. Finally, the mothers were asked about their intention to purchase NAS infant cereal, since $50 \%$ of infant cereals in Taiwan were with NAS claim [20].

The pilot study included 32 mothers who had a child aged between 4 months and 3 years. Survey items were tested for consistency, comprehensibility, and ambiguity. Five child nutrition and statistical professionals reviewed and revised the questionnaire. Cronbach's $\alpha$ was performed to assess the intercoder reliability. The generally accepted lower limit for Cronbach's $\alpha$ value is 0.600 [31]. Final Cronbach's $\alpha$ values for each subscale of the questionnaire were in the range of $0.627-0.884$ (attitude toward NAS infant cereal $=0.803$; importance of sugar content $=0.627$; trust in package information $=0.738$; health awareness $=0.884$; purchase intention for NAS infant cereal $=0.859$ ).

\subsection{Measures}

The dependent variable of purchase intention for NAS infant cereal was measured using two statements: "It is highly likely that I will purchase NAS infant cereal" ( 1 = highly unlikely; $5=$ highly likely) and "I would recommend NAS infant cereal to my friends and family" ( $1=$ highly unlikely; 5 = highly likely). The total score of purchase intention was between 2 and 10 points.

The independent variables that were potential predictors included demographic characteristics and mothers' sugar-related knowledge, sugar-related attitudes, and health awareness. Sugar-related knowledge included statements on "sugar and health," "sugar and food," "infant cereal and nutrition," and "sugar intake." Mothers were asked to determine whether the statements were correct, with higher scores indicating a higher knowledge level. The total knowledge scores were between 0 and 12 points. Sugar-related attitudes included statements on "attitude toward NAS infant cereal," "importance of sugar content," "trust in package information," and "Perception of nutrition label," and were rated using a 5-point Likert scale ranging from "strongly agree" to "strongly disagree," with scores in the range of 4-20, 2-10, 2-10, and 1-5, respectively. Health awareness was measured by five questions based on the same 5-point Likert scale, providing a total score between 5 and 25 points [32].

\subsection{Statistical Analysis}

Data were analyzed using SPSS version 18.0 and the PROCESS add-on developed by Hayes [33]. Descriptive statistics were used for analyzing participants' demographic characteristics and scores on the health awareness, knowledge, attitude, and purchase intention scales. One-way analysis of variance (ANOVA) and an independent-sample $t$ test were used to compare scores on sugar-related knowledge, sugar-related attitude, health awareness, and purchase intention scales across participant demographic characteristics, followed by a Scheffe post hoc test. The correlations between mothers' sugar-related knowledge, sugar-related attitude, health awareness, and purchase intention were tested using the Pearson product-moment correlation coefficient. Multiple linear regressions of intention on knowledge, attitude, and health awareness were performed to identify significant predictors. Bootstrapping was used to test the significance of the indirect effects of knowledge on purchase intention in a mediation model [34]. Statistical significance was set at $p<0.05$.

\section{Results}

\subsection{Participant Characteristics}

Of the 1535 participants who answered the online questionnaires, 940 were considered eligible and 595 were excluded because they had no experience of using infant cereal, no children aged 4 months to 
3 years, or did not complete the questionnaire. Table 1 presents the demographic characteristics of the sample population.

The majority $(70.7 \%)$ of the participants were $\geq 31$ years old. Most of those who completed the questionnaire were educated at university level or above $(92.6 \%)$ and did not have a medical background $(81.9 \%)$. Nearly two-thirds of the participants had a household income of more than NT\$50,000.

Table 1. Demographic characteristics of mothers with a child aged between 4 months and 3 years ${ }^{1}$.

\begin{tabular}{|c|c|c|}
\hline & $N$ & $\%$ \\
\hline Total & 940 & 100.0 \\
\hline \multicolumn{3}{|l|}{ Age (years) } \\
\hline$\leq 30$ & 275 & 29.3 \\
\hline $31-34$ & 381 & 40.5 \\
\hline$\geq 35$ & 284 & 30.2 \\
\hline \multicolumn{3}{|l|}{ Education } \\
\hline$\leq$ High school & 70 & 7.4 \\
\hline Undergraduate & 687 & 73.1 \\
\hline$\geq$ Graduate & 183 & 19.5 \\
\hline \multicolumn{3}{|l|}{$\begin{array}{c}\text { Medical } \\
\text { background }\end{array}$} \\
\hline No & 770 & 81.9 \\
\hline Yes & 170 & 18.1 \\
\hline \multicolumn{3}{|l|}{ Parity } \\
\hline First & 587 & 62.4 \\
\hline Not first & 353 & 37.6 \\
\hline \multicolumn{3}{|l|}{$\begin{array}{c}\text { Income, } \\
\text { NT\$/month }\end{array}$} \\
\hline$\leq 50,000$ & 340 & 36.2 \\
\hline$>50,000$ & 600 & 63.8 \\
\hline \multicolumn{3}{|l|}{$\begin{array}{l}\text { Child's age, } \\
\text { months }\end{array}$} \\
\hline $4-12$ & 438 & 46.6 \\
\hline $13-24$ & 344 & 36.6 \\
\hline $25-36$ & 158 & 16.8 \\
\hline
\end{tabular}

\subsection{Sugar-Related Knowledge}

Table 2 presents the correct rate of mothers' sugar-related knowledge. The total average correct rate was $61.2 \%$. The "sugar and food" and "sugar intake" sections had the lowest correct rates. Most participants knew that excessive free sugar intake is harmful to children's health. In the "sugar and food" section, $93 \%$ of the mothers were unaware that natural fruit sugar is not healthier than fructose added during processing, $40 \%$ considered NAS to signify that the product is sugar free, and $74.9 \%$ did not know that sweetness is derived from ingredients aside from added sugar. In the "sugar intake" section, $78.1 \%$ of the mothers did not know that daily free sugar intake should be less than $10 \%$ of total calories, and half of them did not know that carbohydrates are different from sugar. 
Table 2. Sugar-related knowledge and the correct rate of mothers with a child aged between 4 months and 3 years.

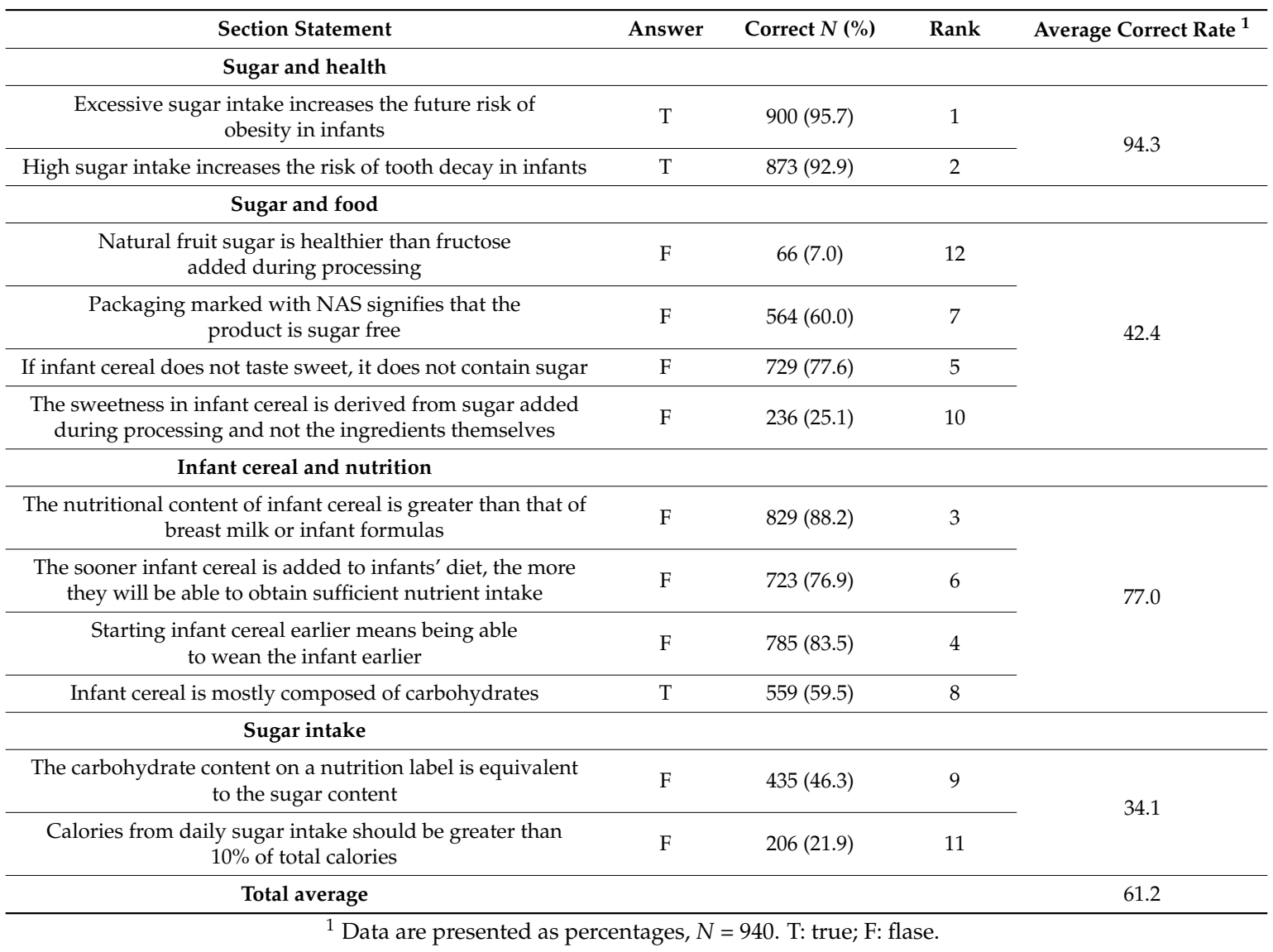

\subsection{Sugar-Related Attitude}

Table 3 presents the mothers' attitudes toward sugar-related information. More than half of the mothers had a positive attitude toward NAS infant cereal. Compared with other infant cereals, $74.0 \%$ of the mothers believed that NAS infant cereal contained less sugar, and $70.9 \%$ of them believed that it was healthier. Most of the mothers also believed that noting the sugar content in a product was important. However, only half of the mothers believed the information on the package, and only $38.9 \%$ of them trusted nutrition claims. Only $25 \%$ of the mothers considered nutrition labels easy to understand.

Table 3. Sugar-related attitude and the average score of mothers with a child aged between 4 months and 3 years ${ }^{1}$.

\begin{tabular}{cccc}
\hline Section Statement & Agree & Neutral & Disagree \\
\hline $\begin{array}{c}\text { Attitude toward NAS infant cereal } \\
\text { Infant cereal with NAS marked on the packaging is healthier } \\
\text { than other types }\end{array}$ & $666(70.9)$ & $190(20.2)$ & $84(8.9)$ \\
\hline $\begin{array}{c}\text { Infant cereal with NAS marked on the packaging is more } \\
\text { natural than other types }\end{array}$ & $510(54.3)$ & $255(27.1)$ & $175(18.6)$ \\
\hline $\begin{array}{c}\text { Infant cereal with NAS marked on the packaging has lower } \\
\text { sugar content than other types }\end{array}$ & $696(74.0)$ & $157(16.7)$ & $87(9.3)$ \\
\hline $\begin{array}{c}\text { I believe that feeding my babies infant cereal with NAS can } \\
\text { lower their future risk of obesity }\end{array}$ & $474(50.4)$ & $300(31.9)$ & $166(17.7)$ \\
\hline $\begin{array}{c}\text { Importance of sugar content } \\
\text { Sugar should not be added to infant cereal }\end{array}$ & $716(76.2)$ & $196(20.9)$ & $28(3.0)$ \\
\hline
\end{tabular}


Table 3. Cont

\begin{tabular}{|c|c|c|c|}
\hline Section Statement & Agree & Neutral & Disagree \\
\hline $\begin{array}{l}\text { When purchasing infant cereal, it is crucial to pay attention to } \\
\text { sugar content }\end{array}$ & $779(82.9)$ & $149(15.9)$ & $12(1.3)$ \\
\hline \multicolumn{4}{|l|}{ Trust in package information } \\
\hline $\begin{array}{l}\text { I believe that the nutrition labels on infant cereal packaging } \\
\text { are trustworthy }\end{array}$ & $530(56.4)$ & $342(36.4)$ & $68(7.2)$ \\
\hline $\begin{array}{l}\text { I believe that nutrition claims such as "no added sugar" } \\
\text { are trustworthy }\end{array}$ & $366(38.9)$ & $423(45.0)$ & $151(16.1)$ \\
\hline \multicolumn{4}{|l|}{ Perception of nutrition label } \\
\hline $\begin{array}{l}\text { I find the nutrition label on infant cereal packaging } \\
\text { easy to understand }\end{array}$ & $235(25.0)$ & $405(43.1)$ & $300(31.9)$ \\
\hline
\end{tabular}

\subsection{Knowledge, Attitude, Health Awareness, and Purchase Intention by Demographic Characteristics}

Table 4 presents the scores on sugar-related knowledge, attitudes, health awareness, and purchase intention across demographic characteristics. Mothers who had graduate degrees or above and had a medical background and household income of more than NT\$50,000 had significantly higher scores in sugar-related knowledge. Mothers who were older, had a higher education level and had only one child were significantly more likely to agree that nutrition labels were easy to understand than the others. The mothers' health awareness in our study was high $(21.05 \pm 2.70$; total score $=25)$. The health awareness of mothers with a medical background (21.62 \pm 2.60$)$ was significantly higher than the those who without such background (20.92 \pm 2.71$)$. Mothers' purchase intention for NAS infant cereal was high $(7.59 \pm 1.43$; total score $=10)$, and no differences in mothers' purchase intention were observed among different demographic characteristics.

Table 4. Sugar-related knowledge, attitude, health awareness, and purchase intentions by demographic characteristics of mothers with a child aged between 4 months and 3 years ${ }^{1}$.

\begin{tabular}{|c|c|c|c|c|c|c|c|}
\hline & \multirow[b]{2}{*}{$\begin{array}{l}\text { Sugar-Related } \\
\text { Knowledge }\end{array}$} & \multicolumn{4}{|c|}{ Sugar-Related Attitude } & \multirow[b]{2}{*}{$\begin{array}{c}\text { Health } \\
\text { Awareness }\end{array}$} & \multirow[b]{2}{*}{$\begin{array}{l}\text { Purchase } \\
\text { Intention }\end{array}$} \\
\hline & & $\begin{array}{c}\text { Attitude } \\
\text { Toward NAS } \\
\text { Infant Cereal }\end{array}$ & $\begin{array}{c}\text { Importance } \\
\text { of Sugar } \\
\text { Content }\end{array}$ & $\begin{array}{l}\text { Trust in } \\
\text { Package } \\
\text { Information }\end{array}$ & $\begin{array}{l}\text { Perception of } \\
\text { Nutrition } \\
\text { Label }\end{array}$ & & \\
\hline Total score & 12 & 20 & 10 & 10 & 5 & 25 & 10 \\
\hline All Age (years) & $7.35 \pm 1.99$ & $14.35 \pm 2.74$ & $8.19 \pm 1.31$ & $6.82 \pm 1.44$ & $2.88 \pm 0.89$ & $21.05 \pm 2.70$ & $7.59 \pm 1.43$ \\
\hline$<30$ & $7.18 \pm 1.97$ & $14.26 \pm 2.66$ & $8.05 \pm 1.39$ & $6.78 \pm 1.40$ & $3.02 \pm 0.86^{\mathrm{a}}$ & $21.10 \pm 2.75$ & $7.59 \pm 1.39$ \\
\hline $31-34$ & $7.39 \pm 1.98$ & $14.39 \pm 2.76$ & $8.22 \pm 1.30$ & $6.85 \pm 1.44$ & $2.82 \pm 0.91^{b}$ & $20.93 \pm 2.68$ & $7.55 \pm 1.47$ \\
\hline$>35$ & $7.45 \pm 2.02$ & $14.37 \pm 2.80$ & $8.29 \pm 1.22$ & $6.80 \pm 1.47$ & $2.82 \pm 0.89^{b}$ & $21.17 \pm 2.70$ & $7.63 \pm 1.40$ \\
\hline \multicolumn{8}{|l|}{ Education } \\
\hline$\leq$ High school & $5.97 \pm 2.32^{c}$ & $13.93 \pm 3.06$ & $8.01 \pm 1.54$ & $6.64 \pm 1.55$ & $2.49 \pm 0.78^{c}$ & $20.46 \pm 2.85$ & $7.74 \pm 1.34$ \\
\hline Undergraduate & $7.31 \pm 1.95^{b}$ & $14.42 \pm 2.71$ & $8.20 \pm 1.29$ & $6.80 \pm 1.42$ & $2.86 \pm 0.88^{b}$ & $21.09 \pm 2.65$ & $7.61 \pm 1.44$ \\
\hline$\geq$ Graduate & $8.02 \pm 1.69^{\mathrm{a}}$ & $14.24 \pm 2.72$ & $8.24 \pm 1.28$ & $6.94 \pm 1.43$ & $3.09 \pm 0.94^{\mathrm{a}}$ & $21.14 \pm 2.81$ & $7.43 \pm 1.41$ \\
\hline \multicolumn{8}{|l|}{$\begin{array}{c}\text { Medical } \\
\text { background }\end{array}$} \\
\hline No & $7.18 \pm 2.00^{b}$ & $14.40 \pm 2.72$ & $8.17 \pm 1.32$ & $6.85 \pm 1.45$ & $2.86 \pm 0.88$ & $20.92 \pm 2.71^{b}$ & $7.52 \pm 1.47$ \\
\hline Yes & $8.08 \pm 1.77^{\mathrm{a}}$ & $14.11 \pm 2.83$ & $8.28 \pm 1.23$ & $6.67 \pm 1.34$ & $2.94 \pm 0.93$ & $21.62 \pm 2.60^{\mathrm{a}}$ & $7.60 \pm 1.42$ \\
\hline \multicolumn{8}{|l|}{ Parity } \\
\hline First & $7.29 \pm 2.04$ & $14.31 \pm 2.74$ & $8.20 \pm 1.33$ & $6.83 \pm 1.46$ & $2.94 \pm 0.91^{\mathrm{a}}$ & $20.99 \pm 2.78$ & $7.60 \pm 1.43$ \\
\hline Not first & $7.44 \pm 1.90$ & $14.40 \pm 2.74$ & $8.17 \pm 1.28$ & $6.79 \pm 1.40$ & $2.77 \pm 0.86^{b}$ & $21.15 \pm 2.57$ & $7.57 \pm 1.43$ \\
\hline \multicolumn{8}{|l|}{ Income } \\
\hline$\leq 50,000$ & $7.00 \pm 1.99^{b}$ & $14.44 \pm 2.73$ & $8.19 \pm 1.31$ & $6.82 \pm 1.46$ & $2.84 \pm 0.87$ & $21.10 \pm 2.73$ & $7.70 \pm 1.41$ \\
\hline$>50,000$ & $7.54 \pm 1.96^{\mathrm{a}}$ & $14.29 \pm 2.75$ & $8.19 \pm 1.31$ & $6.82 \pm 1.42$ & $2.90 \pm 0.91$ & $21.03 \pm 2.69$ & $7.52 \pm 1.43$ \\
\hline
\end{tabular}




\subsection{Factors Related to Purchase Intention}

Table 5 presents the correlations among sugar-related knowledge, sugar-related attitude, health awareness, and purchase intention. Significant negative correlations were observed between "sugar-related knowledge" and "attitude toward NAS infant cereal" (-0.152) and between "sugar-related knowledge" and "purchase intention" (-0.083), however, both of them are weak. A significant positive correlation was observed between "attitude toward NAS infant cereal" and "purchase intention," between "importance of sugar content" and "purchase intention," between "trust in package information" and "purchase intention" and between "health awareness" and "purchase intention".

Table 5. Correlation between sugar-related knowledge, attitude, health awareness and the purchase intention for NAS infant cereal of mothers with a child aged between 4 months and 3 years.

\begin{tabular}{|c|c|c|c|c|c|c|c|}
\hline & (1) & (2) & (3) & (4) & (5) & (6) & (7) \\
\hline (1) Sugar-related knowledge & 1 & & & & & & \\
\hline (2) Attitude toward NAS infant cereal & $-0.152 * *$ & 1 & & & & & \\
\hline (3) Importance of sugar content & $0.164 * *$ & $0.201 * *$ & 1 & & & & \\
\hline (4) Trust in package information & $-0.118^{* *}$ & $0.477^{* *}$ & $0.106^{* *}$ & 1 & & & \\
\hline (5) Perception of nutrition label & $0.182 * *$ & 0.003 & -0.066 & $0.091 * *$ & 1 & & \\
\hline (6) Health awareness & $0.140 * *$ & $0.104 * *$ & $0.293 * *$ & 0.046 & -0.067 & 1 & \\
\hline (7) Purchase intention & $-0.083 *$ & $0.492 * *$ & $0.359^{* *}$ & $0.406^{* *}$ & 0.006 & $0.200 * *$ & 1 \\
\hline
\end{tabular}

${ }^{*} p<0.05,{ }^{* *} p<0.01$, by Pearson correlation coefficient ; these values indicate significant differences; (1) represent sugar-related knowledge; (1) represent sugar-related knowledge; (2), (3), (4), (5) represent sugar-related attitude; (6) represent health awareness; (7) represent purchase intention.

Table 6 presents the results of the multiple regressions for predicting mothers' purchase intention for NAS infant cereal. After adjustment for demographic characteristics, the model explained 34.6\% of the purchase intentions. Mothers with a more positive attitude toward NAS infant cereal exhibited a higher degree of trust in package information, considered sugar content in products to be important, had a higher level of health awareness, and had a higher purchase intention for NAS infant cereal.

Table 6. Multiple regressions to predict the purchase intentions for NAS infant cereal of of mothers with a child aged between 4 months and 3 years.

\begin{tabular}{ccccc}
\hline Independent Variable & Adjusted $\boldsymbol{R}^{\mathbf{2}}$ & $\boldsymbol{\beta}$ & $\mathbf{9 5 \%}$ CI & $\boldsymbol{P}$ \\
\hline Sugar-related knowledge & 0.346 & 0.570 & $(-0.380$ to 1.520$)$ & 0.239 \\
\hline Sugar-related attitude & & -0.036 & $(-0.079$ to 0.006$)$ & 0.095 \\
\hline Attitude toward NAS infant cereal & & & \\
Importance of sugar content & & & $(0.136$ to 0.201$)$ & $<0.001^{*}$ \\
Trust in package information & 0.284 & $(0.221$ to 0.347$)$ & $<0.001^{*}$ \\
Perception of nutrition label & 0.213 & $(0.153$ to 0.274$)$ & $<0.001^{*}$ \\
\hline Health awareness & 0.036 & $(-0.053$ to 0.125$)$ & 0.426 \\
\hline
\end{tabular}

Dependent variable: purchase intention for NAS infant cereal. Adjusted for age, education, medical background, parity, and household income. ${ }^{*} p<0.05$ indicates significant difference, CI: confidence interval.

\subsection{Mediating Variable Between Knowledge and Purchase Intention}

The multiple regressions provided no evidence that sugar-related knowledge can significantly predict purchase intention (Table 6). Figure 1 presents the mediating model among the variables; after ajusted age, education, medical background, parity, and household income, the direct effect of sugar-related knowledge on purchase intention $\left(C^{\prime}\right)$ was not significant (model B). However, the effects of sugar-related knowledge on attitude toward NAS infant cereal was significant. When the mediating variable (attitude toward NAS infant cereal) was considered, sugar-related knowledge had 
no significant direct effect on purchase intention $\left(C^{\prime}=-0.034\right)$. Accordingly, attitude toward NAS infant cereal was observed to mediate the relation between knowledge and purchase intention in this context. The effect of knowledge on purchase intention was evident only through the variable attitude toward NAS infant cereal $\left(B=0.166^{* * *}\right)$. The presence of the variable affected the relationship between sugar-related knowledge and purchase intention. Mothers' sugar-related knowledge had a significant negative effect on attitude toward NAS infant cereal $\left(\mathrm{A}=-0.187^{* * *}\right)$, which in turn had a significant positive effect on purchase intention for NAS infant cereal.

A. Model with Knowledge effect

\begin{tabular}{|c|c|c|}
\hline $\begin{array}{c}\text { Sugar-related } \\
\text { knowledge }\end{array}$ & $\mathrm{C}=-0.065^{*}$ & $\begin{array}{c}\text { Purchase intention } \\
\text { on NAS infant cereal }\end{array}$ \\
\cline { 2 - 4 }
\end{tabular}

B. Model with mediation design

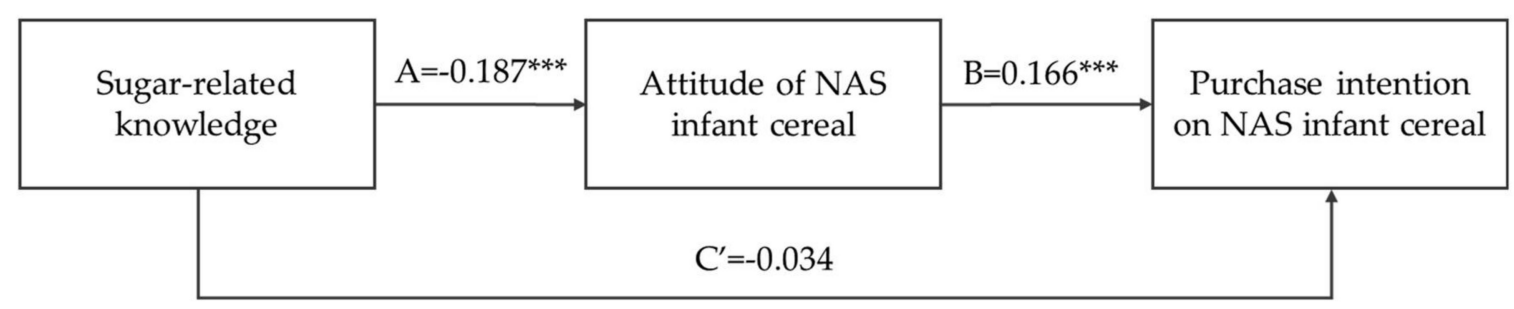

Figure 1. Mediating variable in the relationship between sugar-related knowledge and purchase intention of mothers with a child aged between 4 months and 3 years. Regression coefficient for (A) C: the direct affect model for the association between sugar-related knowledge and purchase intention on NAS infant cereal and (B) the mediator model accounting for attitude of NAS infant cereal. A: the association between sugar-related knowledge and attitude of NAS infant cereal; B: the association between between attitude of NAS infant cereal and purchase intention on NAS infant cereal ; $C^{\prime}$ : the effect of sugar-related knowledge on purchase intention adjusting for attitude of NAS infant cereal.

\section{Discussion}

The present study determined that "attitude toward NAS infant cereal" is a crucial predictor of mothers' purchase intention for NAS infant cereal. This finding is consistent with those of several other studies. Harris et al. found that parents believed that cereals with nutrition-related claims were more nutritious overall and might provide specific health-related benefits for their children; these beliefs predicted a greater willingness to buy the cereal [25]. Dixon et al. also indicated that nutrient claims on the labels of energy-dense and nutrient-poor children's foods led parents to perceive these products to be more nutritious, thereby increasing their purchase intention [24]. Munsell et al. reported that the nutrition and health claims on SSB packaging were important for predicting parents' purchase decisions for children's sugary drinks [23]. Other studies have also found that consumers have a "positivity bias" toward products with nutrition claims, which indicates that consumers provide a higher estimation of the product in general $[35,36]$. These findings provide evidence that health- and nutrition-related claims increase the perception of the healthiness of products and purchase intention for products among parents and consumers, irrespective of the real nutritional quality of these food products or SSBs. 
Our study demonstrated a significant negative correlation between the mothers' sugar-related knowledge and attitude toward NAS infant cereal. Miller and Cassady observed that people's nutrition knowledge affected their attitude toward nutrition and health claims, in one of the few investigations on this topic [37]. In our study, $40 \%$ of the mothers misunderstood NAS to mean "sugar free," and $50-70 \%$ of the mothers had the incorrect expectation that NAS infant cereal is more natural, healthy, and has less sugar content compared with other infant cereals. However, NAS infant cereal or other infant food products with nutrition claims may actually contain more sugar than other infant foods. A previous study in Taiwan found that $72.9 \%$ of NAS infant food contained more than $10 \%$ calories from sugar; this might be because some infant food such ascereal or pure fruit puree contains natural sugar [20]. Several studies have also reported that many infant and toddler foods with nutrition claims also contain high sugar content or less healthy than those without claims [38-40]. In the United States, more than half of children's food products with health or nutrition claims were found to contain more than $20 \%$ calories from sugar [38]. Lapierre et al. reported that in the southeastern United States, children's foods with the most nutrition and child-friendly claims had the highest sugar content [39]. In Brazil, half of children's foods had nutrition claims, and $74.1 \%$ of these were classified as being "less healthy" [40]. Therefore, a product with nutrition claims is not necessarily healthy for children. Another study reported that women and people with children exhibited a higher interest in nutrition claims than people without children [41]. If mothers with young children are misled, a negative impact on the children's health may result.

Previous studies have reported that in Taiwan, children's free sugar intake from snacks and beverages is higher than the intake recommended by the WHO $[13,14]$. These findings indicate that parents and caregivers in Taiwan provide children with high amounts of sweet foods and beverages. Our study demonstrated an indirect effect between sugar-related knowledge and purchase intention. Through the mothers' attitudes toward NAS infant cereal, sugar-related knowledge has a significant negative effect on purchase intention for NAS infant cereal. This observation is in concordance with a previous study, which found that knowledge affected purchase behavior by influencing attitude [42]. A previous study reported that mothers' nutrition knowledge affects their feeding behavior [26]. Our study revealed that mothers with poor sugar-related knowledge misunderstood the NAS claim, potentially leading to unhealthy choices for children's food and excessive sugar consumption by their children. A study confirmed that knowledge about the adverse effects of SSB was negatively associated with SSB intake among adults [43]. Another study found that parental knowledge about the American Academy of Pediatrics guidelines on juice was negatively associated with their children's consumption of juice and SSBs [27]. Improving parental knowledge was demonstrated to reduce the consumption of SSBs among young children [44]. Our study confirmed that mothers with higher sugar-related knowledge had a lower intention to purchase NAS infant cereal.

Our study determined that the accuracy rate of knowledge on "sugar and food" and "sugar intake" among the mothers were lower than those of the other items. More than $90 \%$ of the mothers believed that natural fruit sugar is healthier than fructose added during processing. A previous study found that consumers perceive a breakfast cereal labeled as containing "fruit sugar" to be healthier than one labeled as containing "sugar" [45]. An online survey in the United Kingdom also reported that many consumers (69-89\%) misclassify fruit juice as natural sugars and do not avoid these sugars in their daily diet [46]. In our study, $74.9 \%$ of mothers believed that the sweetness in infant cereal was derived from sugar added during processing and not the ingredients themselves. However, a part of the sweetness is in fact derived from the ingredients, such as the sugar in fruit. Approximately $80 \%$ of the mothers in this study did not know that free sugar intake should be less than $10 \%$ of total energy intake. This result is similar to that obtained in the UK study [46]. However, in our study, most of the mothers knew that excessive free sugar intake by infants may lead to health problems. Yet mothers may not know how to determine the amount of sugar in products, because $53.7 \%$ of them did not know the difference between sugar and carbohydrates. Future research should explore strategies to 
improve mothers' knowledge of sugar through education, particularly to clarify their understanding of the healthiness and classification of sugar.

A previous study in Taiwan found that $81 \%$ of advertisements for complementary food products contained claims concerning health function or nutrient content [47]. However, in our study, the mothers had incorrect expectations of the NAS nutrition claim on children's food packaging. Previous studies have also found that many parents have a positive attitude toward products with nutrition claims and consider these to be healthier than products without such claims [23-25]. In the United States, to prevent such claims from misleading parents or caregivers when they attempt to make healthy choices for their children, no nutritional content claims can be made on the food products intended for use for infants and children younger than 2 years [48]. In the European Union, to prevent consumers from misunderstanding that NAS indicates "less sugar" or "sugar free," if sugar is naturally present in the food, the claim "contains naturally occurring sugar" should appear on the label [49]. In Taiwan, there is no rule for NAS claims and no particular standard for other nutrition claims on infant and young children's food. However, a study in Taiwan found that a high percentage of NAS infant food contained more than $10 \%$ sugar content [20]. Our study found that a high percentage of mothers have incorrect expectations of NAS infant cereal, which could increase their purchase intention. To reduce the chances of caregivers being misled by nutrition claims, in addition to improving nutrition education, the government should modify or enhance the regulation of claims on infant food packaging.

Dixon et al. indicated that parents who read nutrition labels when purchasing children's food are less likely to make unhealthy food choices than those who do not [24]. In our study, only $25 \%$ of the mothers considered nutrition labels easy to understand. The other study also reported similar finding that parents thought nutrition information on food package is too much and too technical [50]. A qualitative study in New Zealand found that because parents found nutrition labels difficult to read and interpret owing to the technical presentation forms, they used the list of ingredients to make food choices for their children [22]. Wills at al. also reported that food labeling is important for consumer to when deciding to buy a certain food or beverage [51]. Some studies indicated that the front of packaged system of foods could assist consumers to make healthier food choices, for its placement on the front of the package and to the design characteristics, especially color-coded Multiple Traffic Light labels have found that helping consumers easy to understand the nutrient content level, which could positively influence consumers' choices for healthier food [52,53]. In addition to improving parents' knowledge of nutrition labels and their ability to use it, further research is warranted to develop simple nutrition labels, such as color-coded or healthy logos, to help consumers and parents to understand the nutrient content level and to make healthy food choices.

The present study has some limitations. First, it was based on a convenient sample of mothers and was therefore not representative of the general population. Second, the proportion of mothers with a high degree of education was overrepresented. Notably, despite the group being relatively highly educated, the mothers had low scores about "sugar and food" and "sugar intake". Also, after sugar-related knowledge, attitudes, and health awareness, then asking mother's purchase intention might lead to mother tend to increase their purchase intention. Finally, because the survey was conducted online through social network websites, it may have failed to reach minority groups in terms of both education and income. Thus, these results possibly represent the most favorable circumstances, because less educated mothers may have an even poorer understanding of sugar and nutrition information on food packaging. These results affirm the need for increased regulations of labels on infant and children's food in Taiwan to protect parents from the potentially misleading information conveyed by nutrition claims.

\section{Conclusions}

The common use of nutrition claims on infant and children's food raises crucial public health concerns. We found that mothers with poor sugar-related knowledge may have inaccurate attitudes and expectations toward the nutrition claims of infant food and, thus, have higher purchase intention 
for NAS food. This may lead them to choose less healthy foods, resulting in their children having high sugar intake. These results affirm the need for increased regulations in Taiwan to protect consumers from the potentially misleading information conveyed by nutrition and other claims on infant food packaging. Also, mothers' sugar-related knowledge needs to be improved through nutrition education.

Acknowledgments: We are very grateful for the cooperation and interest of the mothers who participated in this online survey study. This study would not have been possible without their help. We would also like to thank the anonymous reviewers and the editor for their valuable comments.

Author Contributions: Y.C.C. conceived and designed the questionnaires; Y.C.C., Y.-W.C. and T.-Y.C. performed the survey; T.-Y.C., Y.-W.C. and Y.C.C. analyzed the data; J.-S.C. and Y.C.C. were responsible for data interpretation.

Conflicts of Interest: The authors declare no conflict of interest.

\section{References}

1. Bhaskaran, K.; Douglas, I.; Forbes, H.; dos-Santos-Silva, I.; Leon, D.A.; Smeeth, L. Body-mass index and risk of 22 specific cancers: A population-based cohort study of 5.24 million UK adults. Lancet 2014, 384, 755-765. [CrossRef]

2. Malik, V.S.; Popkin, B.M.; Bray, G.A.; Després, J.-P.; Hu, F.B. Sugar sweetened beverages, obesity, type 2 diabetes and cardiovascular disease risk. Circulation 2010, 121, 1356-1364. [CrossRef] [PubMed]

3. Akil, L.; Ahmad, H.A. Relationships between obesity and cardiovascular diseases in four southern states and colorado. J. Health Care Poor Underserved 2011, 22, 61-72. [CrossRef] [PubMed]

4. World Health Organization. Childhood Overweight and Obesity. Available online: http://www.who.int/ dietphysicalactivity/childhood/en/ (accessed on 8 August 2017).

5. Ministry of Health and Welfare of Taiwan. Obesity Prevention of White Paper. Available online: http: / / obesity.hpa.gov.tw/TC/ researchList.aspx?cid=217 (accessed on 5 August 2017).

6. World Health Organization. Diet, Nutrition and the Prevention of Chronic Diseases: Report of a Joint WHO/FAO Expert Consultation. Available online: http:/ /apps.who.int/iris/bitstream/10665/42665/1/ WHO_TRS_916.pdf?ua=1 (accessed on 30 August 2017).

7. Johnson, R.K.; Appel, L.J.; Brands, M.; Howard, B.V.; Lefevre, M.; Lustig, R.H.; Sacks, F.; Steffen, L.M.; Wylie-Rosett, J. Dietary sugars intake and cardiovascular health: A scientific statement from the american heart association. Circulation 2009, 120, 1011-1020. [CrossRef] [PubMed]

8. Pan, L.; Li, R.; Park, S.; Galuska, D.A.; Sherry, B.; Freedman, D.S. A longitudinal analysis of sugar-sweetened beverage intake in infancy and obesity at 6 years. Pediatrics 2014, 134, S29-S35. [CrossRef] [PubMed]

9. Cantoral, A.; Tellez-Rojo, M.M.; Ettinger, A.S.; Hu, H.; Hernandez-Avila, M.; Peterson, K. Early introduction and cumulative consumption of sugar-sweetened beverages during the pre-school period and risk of obesity at 8-14 years of age. Pediatr. Obes. 2016, 11, 68-74. [CrossRef] [PubMed]

10. He, B.; Long, W.; Li, X.; Yang, W.; Chen, Y.; Zhu, Y. Sugar-sweetened beverages consumption positively associated with the risks of obesity and hypertriglyceridemia among children aged 7-18 years in South China. J. Atheroscler. Thromb. 2017, 25, 81-89. [CrossRef] [PubMed]

11. World Health Organization. Sugars Intake for Adults and Children. Available online: http://www.who.int/ nutrition/publications/guidelines/sugars_intake/en/ (accessed on 9 August 2017).

12. Azaïs-Braesco, V.; Sluik, D.; Maillot, M.; Kok, F.; Moreno, L.A. A review of total \& added sugar intakes and dietary sources in Europe. Nutr. J. 2017, 16, 6. [CrossRef] [PubMed]

13. Lyu, L.C.; Yang, Y.C.; Yu, H.W. A long-term follow-up study of sugar sweetened beverages, snacks and desserts, and refined sugar consumption among preschoolers aged 2 to 5 in Taiwan. Taiwan J. Public Health 2013, 32, 346-357. [CrossRef]

14. Lin, P.-Y.; Lin, F.-Y.; Chen, T.-C.; Chen, W.-L.; Doong, J.-Y.; Shikanai, S.; Sarukura, N.; Yamamoto, S. Relationship between sugar intake and obesity among school-age children in Kaohsiung, Taiwan. J. Nutr. Sci. Vitaminol. 2016, 62, 310-316. [CrossRef] [PubMed]

15. Baker, S.S.; Baker, R.D. Early exposure to dietary sugar and salt. Pediatrics 2015, 135, 550-551. [CrossRef] [PubMed]

16. De Cosmi, V.; Scaglioni, S.; Agostoni, C. Early taste experiences and later food choices. Nutrients 2017, 9, 107. [CrossRef] [PubMed] 
17. Foterek, K.; Buyken, A.E.; Bolzenius, K.; Hilbig, A.; Nothlings, U.; Alexy, U. Commercial complementary food consumption is prospectively associated with added sugar intake in childhood. Br. J. Nutr. 2016, 115, 2067-2074. [CrossRef] [PubMed]

18. Maalouf, J.; Cogswell, M.E. Sodium, sugar, and fat content of complementary infant and toddler foods sold in the united states, 2015. Am. J. Clin. Nutr. 2017, 105, 1443-1452. [CrossRef] [PubMed]

19. Cogswell, M.E.; Gunn, J.P.; Yuan, K.; Park, S.; Merritt, R. Sodium and sugar in complementary infant and toddler foods sold in the united states. Pediatrics 2015. [CrossRef] [PubMed]

20. Yu, C.K.; Chang, J.S.; Chen, Y.C. Food claims and nutrition facts of commercial infant foods. PLoS ONE 2018, 13, e0191982. [CrossRef]

21. Abrams, K.M.; Evans, C.; Duff, B.R. Ignorance is bliss. How parents of preschool children make sense of front-of-package visuals and claims on food. Appetite 2015, 87, 20-29. [CrossRef] [PubMed]

22. Maubach, N.; Hoek, J.; McCreanor, T. An exploration of parents' food purchasing behaviours. Appetite 2009, 53, 297-302. [CrossRef] [PubMed]

23. Munsell, C.R.; Harris, J.L.; Sarda, V.; Schwartz, M.B. Parents' beliefs about the healthfulness of sugary drink options: Opportunities to address misperceptions. Public Health Nutr. 2016, 19, 46-54. [CrossRef] [PubMed]

24. Dixon, H.; Scully, M.; Wakefield, M.; Kelly, B.; Chapman, K.; Donovan, R. Parent's responses to nutrient claims and sports celebrity endorsements on energy-dense and nutrient-poor foods: An experimental study. Public Health Nutr. 2011, 14, 1071-1079. [CrossRef] [PubMed]

25. Harris, J.L.; Thompson, J.M.; Schwartz, M.B.; Brownell, K.D. Nutrition-related claims on children's cereals: What do they mean to parents and do they influence willingness to buy? Public Health Nutr. 2011, 14, 2207-2212. [CrossRef] [PubMed]

26. Yabanc1, N.; Kısaç, İ.; Karakuş, S.Ş. The effects of mother's nutritional knowledge on attitudes and behaviors of children about nutrition. Procedia Soc. Behav. Sci. 2014, 116, 4477-4481. [CrossRef]

27. SanGiovanni, C.; Fallar, R.; Green, R.; Mogilner, L. Parental knowledge of AAP juice guidelines is associated with parent and children's consumption of juice and sugar-sweetened beverages in an underserved population. Clin. Pediatr. 2017, 0009922817696466. [CrossRef] [PubMed]

28. Williams, P. Consumer understanding and use of health claims for foods. Nutr. Rev. 2005, 63, $256-264$. [CrossRef] [PubMed]

29. Talati, Z.; Pettigrew, S.; Neal, B.; Dixon, H.; Hughes, C.; Kelly, B.; Miller, C. Consumers' responses to health claims in the context of other on-pack nutrition information: A systematic review. Nutr. Rev. 2017, 75, 260-273. [CrossRef] [PubMed]

30. Andrews, J.C.; Netemeyer, R.G.; Burton, S. The nutrition elite: Do only the highest levels of caloric knowledge, obesity knowledge, and motivation matter in processing nutrition ad claims and disclosures? J. Public Policy Mark. 2009, 28, 41-55. [CrossRef]

31. Lance, C.E.; Butts, M.M.; Michels, L.C. The sources of four commonly reported cutoff criteria. Organ. Res. Meth. 2006, 9, 202-220. [CrossRef]

32. Gould, S.J. Consumer attitudes toward health and health care: A differential perspective. J. Consum. Aff. 1988, 22, 96-118. [CrossRef]

33. Hayes, A.F. My Macros and Code for SPSS and SAS. Available online: http:/ / afhayes.com/spss-sas-andmplus-macros-and-code.html (accessed on 14 August 2017).

34. Bowman, N.A.; Denson, N. The integral role of emotion in interracial interactions and college student outcomes. J. Divers. High Educ. 2011, 4, 223-235. [CrossRef]

35. Patterson, N.J.; Sadler, M.J.; Cooper, J.M. Consumer understanding of sugars claims on food and drink products. Nutr. Bull. 2012, 37, 121-130. [CrossRef] [PubMed]

36. Lynam, A.M.; McKevitt, A.; Gibney, M.J. Irish consumers' use and perception of nutrition and health claims. Public Health Nutr. 2011, 14, 2213-2219. [CrossRef] [PubMed]

37. Miller, L.M.; Cassady, D.L. The effects of nutrition knowledge on food label use. A review of the literature. Appetite 2015, 92, 207-216. [CrossRef] [PubMed]

38. Colby, S.E.; Johnson, L.; Scheett, A.; Hoverson, B. Nutrition marketing on food labels. J. Nutr. Educ. Behav. 2010, 42, 92-98. [CrossRef] [PubMed]

39. Lapierre, M.A.; Brown, A.M.; Houtzer, H.V.; Thomas, T.J. Child-directed and nutrition-focused marketing cues on food packaging: Links to nutritional content. Public Health Nutr. 2016, 20, 765-773. [CrossRef] [PubMed] 
40. Rodrigues, V.M.; Rayner, M.; Fernandes, A.C.; de Oliveira, R.C.; Proenca, R.P.; Fiates, G.M. Nutritional quality of packaged foods targeted at children in brazil: Which ones should be eligible to bear nutrient claims? Int. J. Obes. 2017, 41, 71-75. [CrossRef] [PubMed]

41. Cavaliere, A.; Ricci, E.C.; Banterle, A. Nutrition and health claims: Who is interested? An empirical analysis of consumer preferences in Italy. Food Qual. Prefer. 2015, 41, 44-51. [CrossRef]

42. Aertsens, J.; Mondelaers, K.; Verbeke, W.; Buysse, J.; Huylenbroeck, G.V. The influence of subjective and objective knowledge on attitude, motivations and consumption of organic food. Br. J. Nutr. 2011, 113, 1353-1378. [CrossRef]

43. Park, S.; Onufrak, S.; Sherry, B.; Blanck, H.M. The relationship between health-related knowledge and sugar-sweetened beverage intake among us adults. J. Acad. Nutr. Diet. 2014, 114, 1059-1066. [CrossRef] [PubMed]

44. Mazarello Paes, V.; Hesketh, K.; O'Malley, C.; Moore, H.; Summerbell, C.; Griffin, S.; van Sluijs, E.M.; Ong, K.K.; Lakshman, R. Determinants of sugar-sweetened beverage consumption in young children: A systematic review. Obes. Rev. 2015, 16, 903-913. [CrossRef] [PubMed]

45. Sütterlin, B.; Siegrist, M. Simply adding the word "fruit" makes sugar healthier: The misleading effect of symbolic information on the perceived healthiness of food. Appetite 2015, 95, 252-261. [CrossRef] [PubMed]

46. Tierney, M.; Gallagher, A.M.; Giotis, E.S.; Pentieva, K. An online survey on consumer knowledge and understanding of added sugars. Nutrients 2017, 9, 37. [CrossRef] [PubMed]

47. Chen, Y.C.; Chang, J.S.; Gong, Y.T. A content analysis of infant and toddler food advertisements in taiwanese popular pregnancy and early parenting magazines. J. Hum. Lact. 2015, 31, 458-466. [CrossRef] [PubMed]

48. U.S. Food and Drug Administration. Available online: https://www.accessdata.fda.gov/scripts/cdrh/ cfdocs/cfcfr/CFRSearch.cfm?CFRPart=101 (accessed on 30 August 2017).

49. European Parliament, Council of the European Union. Regulation (EC) No. 1924/2006 of the European Parliament and of the Council of 20 December 2006 on Nutrition and Health Claims Made on Foods. Available online: http:/ / data.europa.eu/eli/reg/2006/1924/oj (accessed on 8 August 2017).

50. Nørgaard, M.K.; Brunsø, K. Families' use of nutritional information on food labels. Food Qual. Prefer. 2009, 20, 597-606. [CrossRef]

51. Wills, J.M.; Schmidt, D.B.; Pillo-Blocka, F.; Cairns, G. Exploring global consumer attitudes toward nutrition information on food labels. Nutr. Rev. 2009, 67, S102-S106. [CrossRef] [PubMed]

52. Maubach, N.; Hoek, J.; Mather, D. Interpretive front-of-pack nutrition labels. Comparing competing recommendations. Appetite 2014, 82, 67-77. [CrossRef] [PubMed]

53. Watson, W.L.; Kelly, B.; Hector, D.; Hughes, C.; King, L.; Crawford, J.; Sergeant, J.; Chapman, K. Can front-of-pack labelling schemes guide healthier food choices? Australian shoppers' responses to seven labelling formats. Appetite 2014, 72, 90-97. [CrossRef] [PubMed] 